\title{
Oceanography
}

CITATION

Abbott, M.R. 2013. From the President-Early career scientists: Funding and

publishing challenges. Oceanography 26(4):7, http://dx.doi.org/10.5670/oceanog.2013.83.

$\mathrm{DOI}$

http://dx.doi.org/10.5670/oceanog.2013.83

COPYRIGHT

This article has been published in Oceanography, Volume 26, Number 4, a quarterly journal of The Oceanography Society. Copyright 2013 by The Oceanography Society. All rights reserved.

USAGE

Permission is granted to copy this article for use in teaching and research. Republication, systematic reproduction, or collective redistribution of any portion of this article by photocopy machine, reposting, or other means is permitted only with the approval of The Oceanography Society. Send all correspondence to: info@tos.org or The Oceanography Society, PO Box 1931, Rockville, MD 20849-1931, USA. 


\section{Early Career Scientists: Funding and Publishing Challenges}

Although increasingly constrained federal budgets are of concern to the entire community, for early career oceanographers, obtaining funding and publishing papers are essential scholarly activities in the promotion and tenure process at academic institutions. There are new pressures as well, especially the imperative to demonstrate broader impacts and societal relevance as well as the near-instantaneous publishing and review process of social media. Are these pressures distorting the pursuit of scientific knowledge and understanding, especially among oceanographers trying to establish their careers and their reputations?

Since review committees rely on evidence of impact, through metrics such as citation indices, early career scientists understandably focus on publishing in high impact journals. In turn, these high impact journals often emphasize papers with novel results as well as those that may have societal relevance. But papers that attempt to replicate prior results or seek to evaluate the applicability of established methods sometimes suffer in this competition with the new and the societally relevant. And funding agencies, in the face of tight budgets, are sometimes reluctant to fund proposals that seem to "plow old ground." Sometimes there is little cost to getting things wrong, but there is a cost to not getting published or funded.

In my essay in the June 2013 issue, I noted that our science is increasingly engaged as part of policy and economic decisions as scientific publishing becomes enmeshed in advocacy relating to issues from climate change to ocean acidification. Papers can draw the attention not only of our peers, but also the attention of the news media. Facing pressures for the novel and the relevant, publications take on new urgency as well as new rewards. For early career oceanographers, the allure of publications that make grand pronouncements on issues of great societal interest may lead them to make overconfident pronouncements to the press. The Economist (October 19, 2013) discussed the growing problem of unreliable research, especially in the area of biomedical science, but our science is not immune. A paper that forecasts doom may generate lots of attention in the popular press and be useful for those with a political or policy agenda, but it might not further our scientific understanding.

Our early career oceanographers also face the growing impact of social media as they publish and do research, especially in areas that may be politically contentious. A controversy erupted in a blog hosted by Scientific American earlier this year regarding apparently inappropriate conversations between scientists. It soon expanded into a much broader "name and shame" episode, which is sometimes common in the world of entertainment but much less so in the world of science communication. Those of us of a certain age remember newsgroups and occasional eruptions of "flame wars." Modern social media and their networks are even more global, immediate, and permanent and can be used to support "microaggression." Especially in areas of science where there are policy and advocacy connections (such as climate change and severe storms, coastal inundation, and carbon regulation), the tools of social media can be used to question the motives of those who publish papers that support one side or the other of a policy debate. An early career scientist whose paper challenges the results of a tenured, full professor in an area of research that is highly charged politically can face intimidating blowback. Instead of healthy and vigorous scientific debate, issues of privilege and power come into play.

Collectively, these developments pose daunting challenges to early career oceanographers in regard to publishing and funding. Research and papers intended to explore and replicate previous work or to question accepted understanding may receive little funding, hinder the path to promotion and tenure, and potentially place one's career and reputation in jeopardy. Young scientists who engage in a cautious cost-benefit analysis might conclude that engaging and publishing "politically correct" research is a better path for career enhancement, especially if it draws favorable attention in both traditional and social media.

Identifying the issues, of course, is easier than proposing answers. But, as a community, we must begin to mentor our graduate students, our postdoctoral researchers, and our early career scientists on how to maintain scientific integrity and intellectual growth in the face of these challenges. As senior scientists, we need to hold ourselves and our colleagues accountable to ensure that vigorous and open scientific debate can continue, even when our scientific and political beliefs are questioned. Our science and our society will be impoverished if skepticism is smothered by political or scientific agendas.

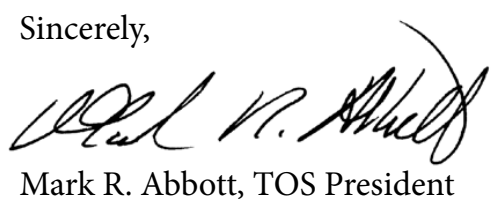

